\title{
Strategy Execution: One Size Does Not Fit All: Evidence from Italian Middle Market
}

\author{
Silvia Vernizzi ${ }^{1}$, Andrea Beretta Zanoni ${ }^{1}$ \& Claudio Zuccolotto \\ ${ }^{1}$ Business Administration Department, University of Verona, Verona, Italy \\ Correspondence: Silvia Vernizzi, Business Administration Department, University of Verona, Verona, Italy. \\ E-mail: silvia.vernizzi@univr.it
}

Received: August 16, 2019

doi:10.5539/ijbm.v14n11p66
Accepted: September 28, 2019

Online Published: October 9, 2019

URL: https://doi.org/10.5539/ijbm.v14n11p66

\begin{abstract}
Despite several studies highlighting the gap between strategy formulation and strategy implementation, strategy execution continues to be considered one of the greatest challenges in strategic management. Beginning from this premise, the present study explores how the gap between strategy formulation and implementation is perceived by middle-sized Italian companies. The basic idea of this study is to verify whether the difficulties that are widely reported in the strategic literature and empirical research of translating strategy into practice also arise in the context of Italian firms, and to examine which are the greatest barriers to successful strategy implementation. To address the research aims, we conduct a survey analysis of 544 middle-sized firms located in Northeast Italy. The findings of the analysis highlight how the main sources of the gap between strategy formulation and execution can be traced to two main factors: the processes through which the implementation step is conducted and the competences and skills necessary to effectively achieve the execution results.

This paper contributes to the existing literature by conducting empirical research on the relevance of strategy execution in the Italian context. The study also has practical implications through its demonstration of the importance of some managerial tools that are highly useful in effective strategy execution.
\end{abstract}

Keywords: strategy execution, strategy implementation, action plan, decision-making processes, skills

\section{Introduction}

It is one thing to formulate strategy, but it is another thing to execute the strategy. Although researchers and professionals have been investigating the significance and operational implications of strategy execution for decades, strategy implementation continues to be considered one of the greatest challenges in strategic management.

Strategy is about designing which development path to take and which target to reach, but only solid execution can ensure the path and target are attained. A flawlessly formulated strategic plan that is not followed by effective execution remains useless (Zagotta \& Robinson, 2002).

Several studies (Richardson, 2008; Sull, Homkes, \& Sull, 2015; The Economist: Intelligence Unit, 2013) have demonstrated that managers recognize the importance of the strategy-execution phase, but report being dissatisfied with the effectiveness of the process.

There are many reasons for the difficulties involved in strategy execution. These reasons can be traced to the following principal factors:

- The scenario assumptions on which strategic plans are based are increasingly uncertain. The volatility of competitive environments requires a continual and systematic rethinking of the chosen development path, accompanied by a continual redefining of strategy and plans (Brueller, Carmeli, \& Drori, 2014; Lafley, Martin, Rivkin, \& Siggelkow, 2012; Lewis, Andriopoulos, \& Smith, 2014; McGrath \& Nerkar, 2004).

- Today, many companies experience difficulties not because they act erroneously, but because they are unable to adapt to changing circumstances, they continue to do what used to be the "right thing", and they become victims of rigid business models (i.e., victims of strategic inertia) (see Doz \& Kosonen, 2010; Rumelt, 1995, 2011).

- Sometimes, strategic choices and actions are perceived as the responsibility of only one person or several 
people. This attitude creates weak communication and a low level of involvement by all people who, if adequately involved, could become "strategy makers" (Mintzberg, Raisinghani, \& Theoret, 1976).

Despite the literature presenting extensive consideration of the relationship between strategy formulation and execution, to date, little is known about the managerial tools firms could and should activate to improve the strategy-execution process.

Moving from a report of worldwide research conducted by The Economist in 2013 (The Economist: Intelligence Unit, 2013) and addressed to 587 senior executives globally, this study aims to explore how the gap between strategy formulation and implementation is perceived by middle-sized Italian companies. The focus on this type of company is motivated by the relevance of the middle market to the Italian economy. In addition, Italian middle-market firms face strong global competition that requires a more structured strategic approach to business and more effective implementation of strategies and plans.

The aim of this study is to verify whether the widely reported difficulties of translating strategy into practice also arise in the context of Italian firms, and to examine which are the greatest barriers to successful strategy implementation.

Thus, we formulate the following research questions:

RQ1 What is the gap between strategy formulation and implementation among middle-sized Italian firms?

$R Q 2$ What are the key factors that enhance this gap?

To address these research questions, we perform a survey analysis as the best option for exploring an under-researched issue. The survey was conducted in January and February 2019, and considered a sample of 544 middle-sized firms located in Northeast Italy.

Using the analysis and discussion of the survey results, we suggest some managerial tools that firms should focus on using to improve their strategy-execution process.

The remainder of the paper is organized as follows. Section 2 examines the literature; Section 3 discusses the research method and describes the survey; Sections 4 and 5 present the results and discuss useful managerial tools that can be used to improve the strategy-execution process; Section 6 concludes the study and identifies the limitations of the study and makes suggestions for future research.

\section{Theoretical Background}

Academic research has been attempting to address the subject of strategy implementation for decades (Ansoff, Declerck, \& Hayes, 1976; Galbraith \& Kazanjian, 1986; Richardson, 2008; Sull et al., 2015). In 1979, Zahn (1979) highlighted how the ability of companies to formulate strategies is more developed than their ability to implement these strategies. Similarly, Hammer (1996) states that a strategic plan without an effective process for implementing it amount to having a pile of worthless documents. According to Kotler (2001), "strategy implementation is the process that turns plans into action assignments and ensures that such assignments are executed in a manner that accomplishes the plan's stated objectives" (p. 36). Nathan (2010) states that "strategy implementation is about getting the strategy as formulated accomplished through employee initiatives. Formulation (no matter how carefully crafted) without a dedicated plan for implementation will amount to little" (p. 38). According to Li, Guohui, and Eppler (2008, p. 3), "strategy implementation has become the most significant management challenge, which all kinds of corporations face at the moment".

Recently a new approach referred to as the "practice approach" has been considered in the strategy literature. This approach recommends focusing on actual strategic practice, that is, it considers that strategy should not be conceptualized as something a company "has", but rather as something a company "does" (Jarzabkowski, 2004; Jarzabkowski, Balogun, \& Seidl, 2007). In this practice approach, corporate-strategy implementation remains greatly significant.

Focusing on decision-making processes and communication, Neilson, Martin, and Powers (2008) identify two main levers for effective strategy execution: the clarification of decision rights (i.e., who owns each decision and who must provide inputs) and the assurance the information flows where it is needed (to build and reinforce network collaboration).

In 2015, Sull et al. (2015) focused on five of the most widely held beliefs about strategy implementation and attempted to replace them with different perspectives. These researchers revealed how managers attribute poor execution to a lack of alignment and a weak performance culture. In particular, the researchers demystified the following execution myths: 1) execution equals alignment; 2) execution means sticking to the plan; 3) communication equals understanding; 4) performance culture drives execution; 5) execution should be driven 
from the top. To respond to these myths, Sull et al. (2015) argue that to execute strategies, companies must foster coordination across units and build the agility to adapt to changing market conditions.

From the practitioner perspective, strategy execution is strongly debated. The interest in strategy execution is demonstrated by the great amount of research conducted on this issue by different corporate institutions. For example, a study by The Economist in March 2013 (The Economist: Intelligence Unit, 2013) surveyed 587 senior executives globally about the issue of execution strategy. The report underlines how senior executives recognize the importance of strategy implementation, but most admit that their companies often struggle to bridge the gap between strategy formulation and its day-to-day implementation. In addition, the respondents identified the number one reason for the success of strategic initiatives as leadership buy-in and support. Most companies either lack the skills, or fail to deploy the personnel needed, for strategy implementation.

Most research in strategic management continues to focus on conceptual analysis rather than on practical implementation. The literature on strategy implementation remains scarce, and there is a growing demand from academia for more empirical research (Baumgartner, 2014; Baumgartner \& Rauter, 2017; Rauter, Jonker, \& Baumgartner, 2017).

\section{Research Method}

The main aim of this study is to verify whether the widely reported difficulties of translating strategy into practice also exist in Italian firms, and to examine which are the greatest barriers to successful strategy implementation. For reaching this aim, the study adopts a qualitative research approach. That is, to achieve the aims of the study, a survey was conducted and analysis through descriptive statistics was applied to interpret the survey results. The survey was addressed to a sample of 544 middle-sized Italian firms belonging to different industries and located in Northeast Italy in the regions of Veneto, Trentino-Alto Adige, and Friuli Venezia Giulia.

As stated, the choice to focus on middle-sized Italian firms was motivated by the relevance of the middle market to the Italian economy, and by the significant opportunities and threats middle-sized Italian firms face, particularly in the context of international competition.

Through the survey, the study addressed the top managers of the sample firms, particularly the chief executive officer (CEO) who in some cases was the entrepreneur, and chief financial officer (CFO) of the firm. We surveyed top management because they are the most powerful and influential members of the organization; they set the company's strategy, make high-stake decisions and ensure the day-to-day operations align with fulfilling the company's strategic goals.

The investigation was conducted in January and February 2019 through an online questionnaire that was created and administered using SurveyMonkey ${ }^{\circledR}$ software. Participants received an email with a link to access the questionnaire. Participants could only complete the questionnaire once because the software checks the internet protocol (IP) address. To increase the response rate, participants were sent a brief presentation of the research and two reminders in two weeks.

The questionnaire had 7 questions aimed at exploring the lack of alignment between strategy formulation and execution and identifying what top managers consider the main barriers to strategy execution. The design of the questionnaire followed the survey conducted by The Economist in 2013 (The Economist: Intelligence Unit, 2013), with some simplification because of the different characteristics of the sample firms and because of the slightly different focus of the survey. That is, our study explored the perception of and main reasons for the problem, focusing on the skills and processes relevant to strategy execution, whereas The Economist's survey focused on the C-level role in the process of strategy implementation.

At the end of the survey period, we addressed 544 firms. One hundred and thirty questionnaires were received but only 114 were completed, providing a retention rate of $21 \%$. Response rate is a critical factor. This is because a low response rate may lead to bias, thus compromising the validity of the research. Extreme caution must be taken before research results are generalized and analyzed. Neuman (2000) stated that the response rate should be from 10-50\%; thus, we consider our response rate adequate and the results of the study generally valid.

As for the demographic details of the sample, the majority of firms (76\%) belong to the manufacturing sector. As for the size, consistently with the middle size market definition, most firms $(67 \%)$ had annual revenues ranging from 10 to 100 million Euros and a number of employees ranging from 50 to $249(61 \%)$. With reference to the internationalization aptitude of the sample, over the last three years, the majority of firms (76\%) had export for less than $10 \%$ of the global revenues and $30 \%$ of firms had foreign productive facilities or commercial subsidiaries. The survey results are presented in the following section. 


\section{Results}

This section presents the results of the 7 survey questions, providing commentary and tabulated results.

The first two questions sought introductory information about the success in performing different activities and explore the gap between the success organizations experience in formulating and implementing strategy.

In details, as for Q1 aimed at assessing the organization' success in performing different activities, $34 \%$ of respondents rated the ability of the organization to formulate strategy as good (32\%) or excellent (2\%) and the percentage increases $(41 \%)$ in relation to the ability of organizations to prioritize strategic initiatives. However, when asked about successfully executing strategy, only $25 \%$ of respondents rated their organizations as good or excellent (Table 1).

Q1: Considering the last three years, how would you rate your organization's success in performing the following activities?

Table 1. Organization success in performing activities

\begin{tabular}{|c|c|c|c|c|c|c|c|c|c|c|}
\hline \multicolumn{11}{|c|}{ Rate on a scale from "very poor" to "excellent" (Frequency and percentage of respondents) } \\
\hline & \multicolumn{2}{|c|}{ Very poor } & \multicolumn{2}{|c|}{ Poor } & \multicolumn{2}{|c|}{ Fair } & \multicolumn{2}{|c|}{ Good } & \multicolumn{2}{|c|}{ Excellent } \\
\hline & Fr. & $\%$ & Fr. & $\%$ & Fr. & $\%$ & Fr. & $\%$ & Fr. & $\%$ \\
\hline $\begin{array}{l}\text { Formulating strategy in response to changing market } \\
\text { conditions }\end{array}$ & 3 & 3 & 30 & 26 & 43 & 38 & 36 & 32 & 2 & 2 \\
\hline $\begin{array}{l}\text { Prioritizing and funding the appropriate strategic } \\
\text { initiatives }\end{array}$ & 2 & 2 & 38 & 33 & 27 & 23 & 47 & 41 & 0 & 0 \\
\hline Successfully executing strategic initiatives & 6 & 5 & 24 & 21 & 55 & 48 & 24 & 21 & 5 & 4 \\
\hline $\begin{array}{l}\text { Feeding lessons from successful strategic initiatives } \\
\text { back into other strategic projects }\end{array}$ & 0 & 0 & 38 & 33 & 46 & 40 & 30 & 27 & 0 & 0 \\
\hline $\begin{array}{l}\text { Feeding lessons from failed strategy } \\
\text { implementation back into other strategic projects }\end{array}$ & 3 & 3 & 15 & 13 & 39 & 34 & 51 & 45 & 6 & 5 \\
\hline
\end{tabular}

The difficulty in executing strategic initiatives was clearly confirmed by the responses to Q2: When asked about the percentage of strategic initiatives successfully implemented, respondents reported that over the past three years, most (53\%) of their strategic initiatives had failed to be successfully implemented (Table 2).

Q2: Considering the last three years, what percentage of strategic initiatives was successfully implemented by your organization?

Table 2. Strategic initiatives successfully implemented

Average percentage of strategic initiatives successfully implemented $47 \%$

Moving from the confirmation of the existence of the problem to the exploration of its main reasons (Table 3), $56 \%$ of the respondents stated that initiatives to implement strategy were poorly thought out, underlining a weakness in the processes that should drive the implementation step. In addition, $53 \%$ of respondents stated that initiatives were poorly resourced. This answer is particularly interesting when considered in relation to the responses to Q1. As noted, $41 \%$ of respondents stated the organization good or even excellent at prioritizing and funding strategic projects. This contradiction may find an explanation in the gap between formulation and implementation (i.e., between theory and practice). That is, when designing strategic initiatives and deciding how to fund them, organizations perform quite well, but when translating strategic initiatives into practice, following what has been decided and concretely supporting strategic initiatives with adequate funding can become more difficult, leading to the process becoming "stuck" and implementation failing.

Moreover, one of the greatest barriers (38\% of respondents) to the implementation process was reported as the lack of alignment between projects for implementing the organization's overall strategy. This can be attributed to having incorrect definitions of the actions necessary to achieve strategic goals and to a lack of communication of the overall strategy; both of which can cause inconsistency between projects that need to be implemented and 
strategy.

Further, an issue related to skills was revealed by Q3, that is, $30 \%$ of respondents reported a lack of change-management skills and project-management skills in their organization.

Q3: What are the biggest barriers to successful strategy implementation in your organization?

Table 3. Barriers to strategy implementation

\begin{tabular}{lcc}
\hline Select up to three (Frequency and percentage of respondents) & Fr. & $\%$ \\
\hline Organization lacks change-management skills & 36 & 30 \\
Initiatives are poorly resourced & 60 & 53 \\
Organization lacks project-management skills & 36 & 30 \\
Communication surrounding strategic projects is poor & 20 & 18 \\
Communication of overall strategy is poor & 32 & 28 \\
Lack of top-management support & 4 & 4 \\
Lack of effort to implement strategic initiatives & 20 & 18 \\
Initiatives to implement strategy are poorly thought out & 64 & 56 \\
Overall strategy is not well thought out & 12 & 10 \\
Projects to implement strategy are not aligned with the organization's strategy & 43 & 38 \\
Other & 16 & 14 \\
Don't know & 4 & 3 \\
\hline
\end{tabular}

The issue of skills is explicitly confirmed and emphasized in Q4 (Table 4). When asked to judge the level of resources obtained by high-priority initiatives, more than $70 \%$ of respondents responded that their organizations has a "personnel problem", both from a quantitative perspective (78\% stated that the number of personnel was insufficient) and from a qualitative perspective (71\% stated that personnel was underskilled).

Q4: Do the high-priority strategic initiatives in your organization usually receive a sufficient level of the following resources?

Table 4. High priority strategic initiatives and resources

\begin{tabular}{lcccc}
\hline (Frequency and percentage of respondents) & \multicolumn{2}{c}{ Yes } & \multicolumn{2}{c}{ No } \\
\hline Investment & Fr. & $\%$ & Fr. & $\%$ \\
Senior leadership sponsorship support & 93 & 82 & 21 & 18 \\
Sufficiently skilled personnel & 93 & 82 & 21 & 18 \\
Sufficient number of personnel & 33 & 29 & 81 & 71 \\
\hline
\end{tabular}

The criticality of personnel skills was also confirmed by Q5 (Table 5), for which $66 \%$ of respondents stated that the success of strategic initiatives success depends on skilled personnel. The results for Q5 reveal that leadership support is another important driver of the success of strategic initiatives (noted by $74 \%$ of respondents as one of the main reasons for strategy success).

An interesting observation emerges from combining the results of Q3 and Q5. When personnel skills are insufficient, they are the source for the failure of strategic initiatives, and such skills are perceived by respondents as not being sufficiently present in high-priority strategic initiatives. In addition, a lack of top-management support is not considered one of the barriers to strategy implementation (with only $4 \%$ of respondents noting it as one of the main barriers to successful strategy implementation), and it was noted that this support is strongly present in high-priority strategic initiatives. That is, according to the respondents, personnel skills are a necessary condition for successful strategy execution, whereas leadership support plays a 
facilitator role.

Q5: When do strategic initiatives succeed in your organization, what are the main reasons for the success?

Table 5. Drivers of strategic initiatives success

\begin{tabular}{lcc}
\hline Select up to three (Frequency and \% of respondents) & & \\
\hline & Fr. & $\%$ \\
\hline Leadership support & 84 & 74 \\
Skilled implementation & 20 & 17 \\
Good fit between specific initiative and general strategy & 40 & 35 \\
Good planning & 52 & 46 \\
Initiative uses skilled personnel & 76 & 66 \\
Good communication & 16 & 14 \\
Initiative receives sufficient funding & 64 & 56 \\
Other & 4 & 3 \\
\hline
\end{tabular}

The adequate support of top management of strategic initiatives was also confirmed by the Q6 results (Table 6), for which $82 \%$ of respondents stated that strategy implementation receives the leadership attention it merits. It seems that while leadership support is a facilitating condition of implementation success, it is not a sufficient condition for this success. In fact, despite high-priority initiatives receiving adequate leadership attention, $82 \%$ of the respondents reported that their organizations struggle to bridge the gap between strategy formulation and implementation.

Q6: Do you agree or disagree with the following?

Table 6. Strategy implementation and organization aptitude

\begin{tabular}{|c|c|c|c|c|}
\hline \multirow[t]{2}{*}{ (Frequency and percentage of respondents) } & \multicolumn{2}{|c|}{ Agree } & \multicolumn{2}{|c|}{ Disagree } \\
\hline & Fr. & $\%$ & Fr. & $\%$ \\
\hline $\begin{array}{l}\text { In our organization, the implementation of strategy is seen more as an } \\
\text { operational task than a distinct, strategic task. }\end{array}$ & 62 & 54 & 52 & 46 \\
\hline $\begin{array}{l}\text { In our organization, strategy implementation receives the leadership } \\
\text { attention it merits. }\end{array}$ & 94 & 82 & 20 & 18 \\
\hline $\begin{array}{l}\text { The adoption of any specific strategic initiative in our organization } \\
\text { depends more on the influence of the most senior executive supporting } \\
\text { it than on an assessment of its value overall. }\end{array}$ & 61 & 53 & 53 & 47 \\
\hline $\begin{array}{l}\text { We often struggle to bridge the gap between strategy formulation and } \\
\text { its practical, day-to-day implementation. }\end{array}$ & 94 & 82 & 20 & 18 \\
\hline $\begin{array}{l}\text { The proportion of strategic-initiative project we successfully completed } \\
\text { has increased in the past three years. }\end{array}$ & 68 & 60 & 52 & 40 \\
\hline
\end{tabular}

The answers to Q7 (Table 7) demonstrate that $91 \%$ of respondents stated that when a decision is made, the activity is not implemented without change, highlighting an important issue related to the implementation process.

Q7: Do you agree or disagree with the following? 
Table 7. Strategic decisions implementation process

\begin{tabular}{|c|c|c|c|c|}
\hline \multirow[t]{2}{*}{ (Frequency and \% of respondents) } & \multicolumn{2}{|c|}{ Agree } & \multicolumn{2}{|c|}{ Disagree } \\
\hline & Fr. & $\%$ & Fr. & $\%$ \\
\hline Our organization is totally focused on day-to-day decisions. & 40 & 35 & 74 & 65 \\
\hline $\begin{array}{l}\text { In our organization, there is no difference between the processes } \\
\text { employed to make day-to-day decisions and those employed to make } \\
\text { strategic decisions. }\end{array}$ & 48 & 42 & 66 & 58 \\
\hline $\begin{array}{l}\text { The rapidity of the decision-making process is consistent with the type } \\
\text { of decision (day-to-day decisions v. strategic decisions). }\end{array}$ & 74 & 65 & 40 & 35 \\
\hline $\begin{array}{l}\text { When a decision is made, the activity is implemented as decided, } \\
\text { without any change. }\end{array}$ & 10 & 9 & 104 & 91 \\
\hline $\begin{array}{l}\text { The effort made by leadership in the decision-making process is } \\
\text { consistent with the importance of the decision. }\end{array}$ & 74 & 65 & 40 & 35 \\
\hline
\end{tabular}

\section{Discussion}

In recent years, researchers and practitioners have debated the importance of the gap between strategy formulation and implementation (Higgins, 2007; Li et al., 2008). Several studies (Sull et al., 2015; The Economist: Intelligence Unit, 2013) have demonstrated that managers recognize the importance of the strategy-execution phase, but also admit their dissatisfaction with the effectiveness of this process.

Beginning from these propositions, the presented study aimed to explore the relevance of strategy execution in the Italian context, both verifying the perception of the existence of the problem and identifying its main reasons. The following synthesizes the main findings of the survey:

1) As expected, Italian firms also struggle to bridge the gap between strategy formulation and implementation.

2) The barriers at the source of this gap lie in several factors, but can be traced to two principal factors:

a. the processes through which the implementation step is conducted

b. the lack of competences and skills necessary to effectively achieve the execution results.

Focusing on these two main factors, this study suggests the following managerial tools that firms should use to improve their process of strategy execution: the action plan, the decision-making process; the composition of work teams.

The findings from the survey reveal that the first step to improving strategy execution is related to the rationalization of the problem (i.e., identifying clearly what implementing strategy means). Only after a clear understanding of the problem the proper solution can be found. This step could be built around the concept of action plan.

The action plan is the tool through which, during the strategic process, choices begin to be implemented. All rationalization of problems related to implementation should begin from an analysis of the action plan.

More specifically, the action plan is the part of the strategic plan in which the principal projects (actions) or lines of action for implementing the strategic choices and attaining the competitive objectives are identified. In practical terms, the action plan is a "to-do" list that specifically describes the timetables, deadlines, roles, responsibilities, costs, and investments required to complete the plan. The action plan can involve any aspect of the life of the firm (e.g., reduced number of personnel, expansion of the sales network, reorganization of distribution arrangements, or merging with a competitor).

The construction of an action plan has the following principal phases:

- identify potential projects instrumental to the implementation of strategic choices

- $\quad$ establish the order of priority among the various potential projects

- for every project, establish deadlines, responsibilities, resources, decisions, etc.

- verify that the various projects are mutually coherent and that overall, there is coherence among the competitive objectives, strategic choices, and potential actions or planned processes

- choose which projects to include in the action plan (the actions or processes to follow).

Once established, the action plan becomes part of the firm's daily course of activities, with adjustments made 
after periodic revisions.

A well-designed action plan can drive the entire process of strategy execution and reduce some of the most significant barriers to strategy implementation, such as the weak design of actions necessary to execute strategy, misalignment of strategic projects and the overall strategy, and the lack of a proper prioritizing of strategic projects (Q3).

However, the utility of the action plan goes far beyond the rationalization of the problem. Every action plan is composed of projects and activities with different characteristics. This diversity makes any attempt to apply a "one-size-fits-all" approach completely inadequate. To turn action plans into true strategy-execution tools, it is necessary to understand the characteristics of the various activities (projects) to differentiate the composition of the work teams and the decision-making processes. For example, projects can be classified according to certain significant dimensions (e.g., the technology or application dimension). When applying the technology dimension, firms can classify strategic initiatives according to the technology that is required to conduct the initiative, distinguishing actions that require technology already possessed by the firm and those that require technology that must be newly acquired or internally developed by the firm. When applying the application dimension, firms can classify strategic initiatives according to whether the applications already exist in the firm (e.g., improving already existing productivity or improving an already existing product) or whether the application is new (e.g., a new product or an initiative that will revolutionize the production processes). In principle, the less conventional the chosen dimensions, the greater the probability of obtaining original and innovative interpretations of the projects.

In addition, each strategic project represented in the action plan is associated with a different risk, which is defined as the probability of the occurrence of harm to the organization related to the failed execution of the project itself. Given the diversity of risk, a key element of the entire process of strategy execution is to understand the risks involved, the probability of these risks occurring, and the possible effects associated with their occurrence.

It is not uncommon for people involved in operational activities to suffer from shortsightedness in relation to risk perception. Stress, pressure to deliver results, excessive involvement in activities that are overly operational (a problem endemic in Italian medium-sized companies), and continuous emergency conditions can often lead to focusing only on risks that are imminent in the short term.

Therefore, for every project, it is useful to prepare a risk analysis that enables monitoring of the probability of risks and the temporal horizon of any associated effect (Cokins, 2009).

Given the differences between projects and the impossibility of dealing with their implementation univocally, it is necessary to understand how, and with which tools the probability of success of the action plan can be optimized. The answer to this is found in the following two factors:

1) decision-making processes

2) composition of the work teams.

One of the most critical and often undervalued aspects is the decision-making process. The survey results demonstrate the criticality of this phase (e.g., Q3 and Q6). In the execution of strategic projects, the focus is often on elements such as the organization, technologies, and areas of application of the products, but rarely is the focus on the decision-making process. However, there is great risk in considering all decisions in the same way, ignoring the fact that decisions differ in organizational complexity, availability, and accuracy of information, as well as because of factors such as the experience of the decision makers and the recurrence of the type of decision. It follows that decisions that are structurally different must be matched with different decision-making processes.

Moreover, decision-making processes must consider the skills required to implement a project (Eisenhardt \& Zbaracki, 1992; Mitchell, Shepherd, \& Sharfman, 2017). The skills issue was clearly significant in the survey results, and as stated, the issue skills relates to the skills necessary to deal with the change management that every organization experiences, and the specific skills necessary to manage the specific project and to implement the strategic initiative (Q4, Q5).

In assembling a project team, skills and hierarchy are usually considered, as they should be, but very rarely are the aptitudes of the team constituents considered. Given that different projects entail different sets of decisions, each work team should be characterized by a different aptitudes (Jarzabkowski, 2008).

Aptitudes can vary significantly among the people in an organization. In any organization, one can find people 
with a strong propensity for action and practical implementation, people with an aptitude more driven toward ideas and knowledge, or people with an aptitude for connection and social interaction.

Clearly, it is not possible to think about the composition of work teams as a preset recipe in which personal aptitudes are the ingredients. Rather, it is necessary to analyze periodically which compositions are best and should be used as a mold for the work team in consideration of specific projects to be implemented and the characteristics of the decisions to be made (Griffin, 2018).

Thus, beginning from the analysis of the survey results, it can be argued that the action plan is a crucial element in rationalizing the problem of strategy formulation and implementation, and attempting to guide the entire execution process. Given that every project included in an action plan has its own features, decision-making processes and the composition of work teams are the elements that if properly considered, can help to improve the effectiveness of the implementation phase, bridging the gap between strategy formulation and execution and driving the competitive success of the firm. In fact, a good strategy that is well executed can transform confused and complicated challenges into challenging and achievable objectives (Mankins \& Steele, 2005; Srivastava \& Sushil, 2013).

Moreover, decoding the ambiguity of an execution process provides motivation to each resource, increasing the chances of success (Frey \& Osterloh, 2001). Thus, strategy and execution can become a self-perpetuating process through the motivational energy and results obtained, which, if supported, guarantee achievement of the long-term objectives of the organization. Excellence in strategy execution can lead to true competitive advantage to pursue and maintain. However, excellence is not found in a preset model. To achieve excellence, what is required is a "sartorial" approach that calls for "tailor-made" calibration of the decision-making processes and the work team in relation to the characteristics (nature and risks) of every project in the action plan.

\section{Conclusions}

This paper aimed to contribute to the existing literature exploring through empirical research the relevance of strategy execution in the Italian context. The study also has practical importance through stressing the importance of some managerial tools important for successful strategy execution (i.e., for implementing the business model).

The survey results confirm, also for the Italian middle-market's firm, the existence of a gap between strategy formulation and implementation, and shed light on some of the main factors at its origin, i.e. a weakness on organization processes and skills.

This study has limitations that must be acknowledged in that it considers a limited sample of firms with specific features both in dimension and in geographic location. Despite these limitations, this explorative study paves the way for future research. Future studies should examine differences (if any) among middle-sized firms and more structured firms in relation to bridging the gap between strategy formulation and implementation. Future research should also compare attitudes toward strategy execution of organizations belonging to different industries or located in different countries to verify the relevance of some institutional, structural, or cultural items.

The results of this preliminary study should be viewed as a first step in an area of research that remains understudied and aims to bridge the gap between strategy formulation and execution, one of the greatest challenges in modern strategic management.

\section{References}

Ansoff, H. I., Declerck, R. P., \& Hayes, R. L. (1976). From strategic planning to strategic management. International Conference on Strategic Management. Vanderbilt University: Wiley.

Baumgartner, R. J. (2014). Managing corporate sustainability and CSR: A conceptual framework combining values, strategies and instruments contributing to sustainable development. Corporate Social Responsibility and Environmental Management, 21(5), 258-271. https://doi.org/10.1002/csr.1336

Baumgartner, R. J., \& Rauter, R. (2017). Strategic perspectives of corporate sustainability management to develop a sustainable organization. Journal of Cleaner Production, 140, 81-92. https://doi.org/10.1016/j.jclepro.2016.04.146

Brueller, N. N., Carmeli, A., \& Drori, I. (2014). How do different types of merger and acquisitions facilitate $\begin{array}{lllll}\text { strategic agility? } \quad \text { California } & \text { Management }\end{array}$ https://doi.org/10.1525\%2Fcmr.2014.56.3.39

Cokins, G. (2009). Performance management: Integrating strategy execution, methodologies, risk, and analytics 
(Vol. 21). John Wiley \& Sons.

Doz, Y. L., \& Kosonen, M. (2010). Embedding strategic agility: A leadership agenda for accelerating business model renewal. Long Range Planning, 43, 370-382. https://doi.org/10.1016/j.lrp.2009.07.006

Eisenhardt, K. M., \& Zbaracki, M. J. (1992). Strategic decision making. Strategic Management Journal, 13(S2), 17-37. https://doi.org/10.1002/smj.4250130904

Frey, B. S., \& Osterloh, M. (Eds.). (2001). Successful management by motivation: Balancing intrinsic and extrinsic incentives. Springer Science \& Business Media.

Galbraith, J. R., \& Kazanjian, R. K. (1986). Strategy implementation. St Paul, MN: West.

Griffin C.R. (2018). Adopting a strategic approach to matching people to job. International Journal of Business and Management, 13(4), 1-10. https://doi.org/10.5539/ijbm.v13n4p1

Hammer, M. (1996). Beyond reengineering: How the process-centered organization is changing our work and our lives. New York, NY: HarperCollins Publishers.

Jarzabkowski, P. (2004). Strategy as practice: Recursiveness, adaptation, and practices-in-use. Organization Studies, 25(4), 529-560. https://doi.org/10.1177\%2F0170840604040675

Jarzabkowski, P., Balogun, J., \& Seidl, D. (2007). Strategizing: The challenges of a practice perspective. Human Relations, 60(1), 5-27. https://doi.org/10.1177\%2F0018726707075703

Jarzabkowski, P. (2008). Shaping strategy as a structuration process. Academy of Management Journal, 51(4), 621-650. https://doi.org/10.5465/amr.2008.33664922

Kotler, P. (2001). Marketing management (10th ed.). London: Pearson Education.

Li, Y., Guohui, S., \& Eppler, M. J. (2008). Making strategy work: A literature review on the factors influencing strategy implementation. ICA Working Paper. University of Lugano, Switzerland.

Lafley, A. G., Martin R., Rivkin J. W., \& Siggelkow, N. (2012), Bringing science to the art of strategy. Harvard Business Review, September, 3-12.

Lewis, M. W., Andriopoulos, C., \& Smith, W. K. (2014). Paradoxical leadership to enable strategic agility. California Management Review, 56(3), 58-77. https://doi.org/10.1525\%2Fcmr.2014.56.3.58

Mankins, M. C., \& Steele, R. (2005). Turning great strategy into great performance. Harvard Business Review, 83(7), 64-72.

McGrath, R. G., \& Nerkar, A. (2004). Real options reasoning and a new look at the R\&D investment strategies of pharmaceutical firms. Strategic Management Journal, 25(1), 1-21. https://doi.org/10.1002/smj.358

Mintzberg, H., Raisinghani, D., \& Theoret, A. (1976). The structure of 'unstructured' decision processes. Administrative Science Quarterly, 21(2), 246-275. https://doi.org/10.2307/2392045

Mitchell, R. J., Shepherd, D. A., \& Sharfman, M. P. (2011). Erratic strategic decisions: When and why managers are inconsistent in strategic decision making. Strategic Management Journal, 32(7), 683-704. https://doi.org/10.1002/smj.905

Nathan, M. L. (2010). 'Lighting tomorrow with today': Towards a (strategic) sustainability revolution. International Journal of Sustainable Strategic Management, 2(1), 29-40. https://doi.org/10.1504/IJSSM.2010.032162

Neilson, G. L., Martin, K. L., \& Powers, E. (2008). The secrets to successful strategy execution. Harvard Business Review, 86(6), 60-70.

Neuman, W. L. (2000). Social research methods: Qualitative and quantitative approaches (4th ed.). Needham Heights, MA: Allyn \& Bacon.

Porter, M. E. (1980). Competitive strategy. New York, NY: Free Press.

Rauter, R., Jonker, J., \& Baumgartner, R. J. (2017). Going one's own way: Drivers in developing business models for sustainability. Journal of Cleaner Production, 140, 144-154. https://doi.org/10.1016/j.jclepro.2015.04.104

Richardson, J. (2008). The business model: An integrative framework for strategy execution. Strategic Change, 17(5/6), 133-144. https://doi.org/10.1002/jsc.821

Rumelt, R. (1995). Inertia and transformation. In C. A. Montgomery (Ed.), An evolutionary perspective: Towards 
a synthesis of evolutionary and resource-based approaches to strategy (pp. 101-132). Norwell, MA: Kluwer Academic Publishers.

Rumelt, R. (2011). Good strategy, bad strategy. New York, NY: Crown Business.

Srivastava, A. K., \& Sushil. (2013). Modeling strategic performance factors for effective strategy execution. International Journal of Productivity and Performance Management, 62(6), 554-582. https://doi.org/10.1108/IJPPM-11-2012-0121

Sull, D., Homkes, R., \& Sull, C. (2015). Why strategy execution unravels-And what to do about it. Harvard Business Review, 93(3), 57-66.

The Economist: Intelligence Unit. (2013). Why good strategies fail. Lessons for the C-suite. Retrieved from https://www.pmi.org/-/media/pmi/documents/public/pdf/learning/thought-leadership/why-good-strategies-fa il-report.pdf

Zagotta, R., \& Robinson, D. (2002). Keys to successful strategy execution. Journal of Business Strategy, 23(1), 30-34. https://doi.org/10.1108/eb040221

Zahn, E. (1979). Strategic planning in the co-ordination of long-term organizational development. Berlin: Dunker \& Humblot.

\section{Copyrights}

Copyright for this article is retained by the author(s), with first publication rights granted to the journal.

This is an open-access article distributed under the terms and conditions of the Creative Commons Attribution license (http://creativecommons.org/licenses/by/4.0/). 